\title{
Steroid scare
}

Some children with asthma and eczema are being deprived of steroids because of fear of side effects. The result is undertreatment, particularly of those most severely affected. The consequences of this may be worse than the potential known side effects.

\section{The need for inhaled steroids in chronic asthma}

The idea that prophylactic inhaled steroids are a last resort is wrong. They offer effective management of asthma for many patients whose symptoms are not controlled by antigen avoidance regimens, bronchodilators, inhaled cromoglycate, or regular slow release theophylline. There should be no hesitation in using inhaled steroids for patients not controlled by bronchodilators or cromoglycate, and persistence of bad attacks, frequent symptoms, or unstable twice daily peak expiratory flow readings warrant prompt treatment with inhaled steroids. Some children are managed for years on large quantities of bronchodilators alone, and repeated requests for bronchodilators should suggest that prophylaxis is required. The underdiagnosis of asthma is now well known, but the problem of undertreatment is less well appreciated.

\section{The safety of inhaled steroids in asthma}

Although $80-90 \%$ of an inhaled dose of steroid is swallowed, it is deactivated in the liver before reaching the systemic circulation. Regular inhaled steroids in therapeutic doses are remarkably free of unwanted systemic effects, such as growth impairment. ${ }^{1}{ }^{2}$ Indeed, relapse of pre-existing atopic eczema or allergic rhinitis is a common problem when changing from systemic to inhaled steroids. Only the question of whether inhaled steroids cause a minor degree of adrenal suppression is unresolved. A report of salivary cortisol concentrations showed no evidence of suppression, ${ }^{3}$ whereas another study reported low nocturnal and early morning plasma cortisol concentrations, ${ }^{4}$ although the clinical relevance of the latter study is doubtful. ${ }^{56}$

\section{Short courses of oral steroids for acute asthma}

Failure of the patient with acute asthma to respond promptly to treatment with bronchodilators is an absolute indication for treatment with steroids. Short courses of steroids are effective and safe, ${ }^{78}$ but the optimal dose and duration of such treatment is not known. Even a single large dose has been shown to be beneficial in adults, ${ }^{9}$ but most children are likely to need three to seven days of treatment. Studies of deaths from asthma both at home and in hospital have repeatedly shown that steroids were not given, which was usually combined with a failure to appreciate the severity of the attack. ${ }^{10-13}$ Some patients die too early in an unexpected attack for steroids to be effective, but while there can never be proof that others would have survived had they received steroids, at least some would probably have done so. The decision to prescribe oral or rectal theophylline instead of short courses of oral prednisolone, when maintenance treatment with bronchodilators, cromoglycate, or steroid aerosols, or both, have already failed, may be a recipe for disaster. Similarly, while the increasing use of nebulised bronchodilators at home has brought benefits, some children are exposed to the real hazards of delayed referral to hospital and arrival in a moribund state $^{1415}$ because a poor response has gone untreated. ${ }^{16}$

\section{The need for maintenance oral steroids in severe asthma}

The efficacy of prophylactic inhaled steroids may lead one to forget that there are a few children with severe intractable asthma who can only be adequately controlled with regular prednisolone or adrenocorticotrophic hormone (ACTH). The temptation to wean patients off regular steroids-for example, when they are sent to residential schoolscan be catastrophic. An unpublished survey of 109 British asthmatic children who had been sent to the Swiss alps reported that most were taken off steroids, but at follow up a few years later seven had died. There are two great dangers with this policy: one is that, although children with asthma often improve when sent to a residential school, they are liable to relapse on returning home for holidays; the other is that after being weaned off long term oral steroids, recovery of a normal hypothalamo/ pituitary/adrenal axis response to stress may take as long as a year, and throughout that period the life of a child with chronic asthma is constantly at risk. ${ }^{17}$ It is worth remembering that suppression of the hypothalamo/pituitary/adrenal axis is far less when prednisolone is given in the early morning rather 
than in the evening. Adverse effects, especially hypothalamo/pituitary/adrenal axis suppression and growth inhibition, are greatly reduced when oral steroids are given in the morning and only on alternate days. The theory that the adverse effect of ACTH on growth is reduced has not been confirmed. ${ }^{18}$ This, combined with the need for injection, now means that ACTH probably has a lesser role in the management of severe atopic disease. When long term systemic steroids are used, cataracts may develop. ${ }^{19}$ Children with severe eczema are considerably more likely to develop cataracts than those with asthma, but this is usually not connected with the administration of steroids.

\section{Topical steroids for atopic eczema}

Treating eczema is quite unlike treating asthma, and far more complicated. The price for undertreatment of severe atopic eczema is disfigurement and handicap; the penalty for overtreatment with steroids is similar. With long term topical steroids, the major worry is skin atrophy, but with careful treatment of facial eczema this complication should not be troublesome.

The different strengths of topical steroids cause confusion among doctors and parents alike. A good example of such a muddle was seen when a two month old infant with a facial rash was prescribed beclomethasone dipropionate (category II, potent). When this was unsuccessful, $0.5 \%$ hydrocortisone was prescribed, but the mother declined to go to the chemist because she knew hydrocortisone was, 'far too strong'.

\section{There are some rules:}

1 Communication. Fear of using safe, mildly potent, topical steroids is a cause of needless suffering. Most parents have the idea that topical steroids are dangerous. Any prescription must therefore be accompanied by an explanation of the different steroid potencies. Conventional potency gradings, as listed in the British National Formulary, ${ }^{20}$ mean nothing to the layman, so an analogy with alcoholic drinks is helpful. There are four categories of topical steroid potency: grade IV, mildly potent, the 'shandy' of the range; grade III, moderately potent, 'sherry'; grade II, potent, 'whisky'; grade I, highly potent, 'pure alcohol'.

In practice the major hazard of topical steroids is skin atrophy, resulting from regular use of the more potent preparations (categories III, II, and I), especially on the face. It is helpful for parents to know that this is virtually impossible to achieve with hydrocortisone. It is common to find circular areas of hypopigmentation in the region of eczematous lesions, especially after the child has been in the sun. Most parents wrongly assume that this is a side effect of the steroid and are helped by being told about the non-specific suppression of pigment production resulting from any localised skin disorder.

2 Dry skin. The skin is invariably dry in atopic eczema, so an ointment based steroid will be more effective than a cream. A potent cream-based preparation can usually be replaced with a weak steroid ointment. The regular use of an emollientfor example, emulsifying ointment-is likely to cut down dryness and may reduce the need for topical steroids. The combination of a topical steroid with an antiseptic (such as clioquinol) may be useful where there has been a previous tendency to crusting, or weeping pustules which are signs of bacterial infection. ${ }^{2 \rho}$

3 Knees, wrists, and ankles. In older children it is common to see severe and heavily lichenified-that is, thickened-patches of eczema confined to the front of the knees, the wrists, and the ankles. Such lesions may not respond well to mildly potent steroids, and here it makes no sense to withhold a category II or III preparation because of fear of skin atrophy.

4 Severe generalised lesions. The larger the area of skin affected, and the more inflamed the skin, the greater is the risk of systemic absorption of a topical steroid. There is a theoretical risk of iatrogenic Cushing's syndrome with the widespread application of topical steroids, but the dearth of reported cases suggests that this is exceedingly rare. While atopic eczema is not a fatal condition, it is easy to forget how severe the resulting handicap and damage can be. To withhold mild or moderately potent steroids in such patients for fear of side effects is unreasonable. Indeed, in a few rare patients who are unresponsive even to the most stringent antigen avoidance regimens, life is only tolerable with the aid of regular systemic steroids.

Growth impairment is a feature of up to $10 \%$ of children with atopic eczema. ${ }^{22}$ There is no evidence that the use of mild or moderately potent topical steroids contributes to this, although the long term use over large areas of skin of potent or very potent preparations, probably inhibits growth. ${ }^{22}$

5 Dilution. Diluting proprietary preparations is misguided: either the dilute result retains the potency of the original preparation; or the efficacy is changed in some uncontrolled way because mixing different vehicles may produce unpredictable changes in bioavailability. Certain substances-for example, 
salicylic acid or urea considerably enhance the skin penetration of steroids. It is better to decide on the potency required and use a proprietary preparation than opt for 'Dr X's ointment' (containing steroid, tar paste, and paraffin), the magic qualities of which are usually attributable to a highly potent steroid.

6 Infection. In theory topical steroids could exacerbate an area of infected eczema. In practice this does not occur, ${ }^{23}$ and the problem is not mistreatment with steroids but failure to recognise and treat infection. ${ }^{21}$ Topical steroids do not precipitate either initial or recurrent infections with herpes simplex. ${ }^{24}$

\section{Conclusions}

The fear of side effects causes some doctors to withhold safe and effective treatment with steroids. Asthma and eczema can both be disabling and handicapping diseases, and in both, undertreatment is currently far more common than overtreatment. Untreated, both diseases can impair growth, and successful treatment usually reverses this.

\section{References}

' Balfour-Lynn L. Growth and childhood asthma. Arch Dis Child 1986;61:1049-55.

2 Bhan GL, Gwynn CM, Morrison-Smith J. Growth and adrenal function of children on prolonged beclomethasone dipropionate treatment. Lancet 1980;i:96-7.

3 Williams H, Read GF, Verrier-Jones ER, Hughes IA. Effect of inhaled beclomethasone dipropionate on saliva cortisol concentrations. Arch Dis Child 1984:59:553-6.

${ }^{4}$ Law CM, Marchant JL, Honour JW, Preece MA, Warner JO. Nocturnal adrenal suppression in asthmatic children taking inhaled beclomethasone dipropionate. Lancet 1986; i:942-4.

5 Ventura A, Strinati R, Longo G. Systemic effects and inhaled beclomethasone dipropionate. Lancet 1986;i:1393.

${ }^{6}$ Morrow-Brown H. Nocturnal adrenal suppression in children taking inhaled beclomethasone dipropionate. Lancet $1986 ; \mathbf{i}: 1269$.
${ }^{7}$ Deshpande A. McKenzie SA. Short courses of steroids in home treatment of children with acute asthma. $\mathrm{Br} \mathrm{Med} J$ 1986;293:169-71.

${ }^{8}$ Houlsby WT, Ng PC, Conway SP. Steroids in home treatment of children with acute asthma. $B r$ Med $J$ 1986;293:758.

${ }^{9}$ Littenberg B, Gluck EH. A controlled trial of methylprednisolone in the emergency treatment of acute asthma. $N$ Engl J Med 1986;314:150-2.

11 Carswell F. Thirty deaths from asthma. Arch Dis Child 1985;60:25-8.

1 Scars MR, Rea HH, Fenwick J, et al. Deaths from asthma in New Zealand. Arch Dis Child 1986:61:6-10.

12 Macdonald JB, Macdonald ET, Seaton A, Williams DA. Asthma deaths in Cardiff 1963-74: 53 deaths in hospital. $\mathrm{Br} \mathrm{Med}$ $J$ 1976;ii:721-3.

13 Macdonald JB, Seaton A. Williams DA. Asthma deaths in Cardiff 1963-74: 90 deaths outside hospital. $\mathrm{Br}$ Med $J$ 1976:i:1493-5.

${ }^{14}$ Kuzemko JA. Near-miss asthma deaths in children. Lance 1985:i:49.

15 Lillington AW, Campbell AN, Poulier RA. Safe drugs for childhood asthma? Lancet 1983:ii:1032-3.

${ }^{16}$ Sears MR. Rea HH, Fenwick J, et al. 75 deaths in asthmatics prescribed home nebulisers. Br Med J 1987;294:477-80.

17 Mellis CM. Phelan PD. Asthma deaths in children-a continuing problem. Thorax 1977;32:29-34.

is Oberger E. Taranger J, Bruning B, Engstrom I, Karlberg J. Long-term treatment with corticosteroids/ACTH in asthmatic children. IV. Skeletal maturation. Acta Paediatr Scand 1986:75:744-9.

${ }^{19}$ Bhagat RG. Chai H. Development of posterior subcapsular cataracts in asthmatic children. Pediatrics 1984:73:626-30.

21 British National Formulary No 11. London: British Medical Association and the Pharmaceutical Society of Great Britain 1986.

21 David TJ, Cambridge GC. Bacterial infection and atopic eczema. Arch Dis Child 1986:61:20-3.

22 Kristmundsdottir F, David TJ. Growth impairment in children with atopic eczema. J Rov Soc Med 1987;80:9-12.

${ }^{23}$ Clement M. du Vivier A. Topical steroids for skin disorders. Oxford: Blackwell Scientific Publications Ltd, 1987.

${ }^{24}$ David TJ, Longson M. Herpes simplex virus infections in atopic eczema. Arch Dis Child 1985;60:338-43.

T J David

Booth Hall Children's Hospital,

Blackley,

Manchester M9 $2 A A$ 